\title{
All-Pass-Filter-based Active Damping for VSCs with LCL Filters Connected to Weak Grids
}

\author{
Javier Roldán-Pérez*, Member, IEEE, Emilio J. Bueno ${ }^{\dagger}$, Member, IEEE, Rafael Peña-Alzola ${ }^{\ddagger}$, Member, IEEE, and \\ Alberto Rodríguez-Cabero ${ }^{\S}$ \\ *javier.roldan@imdea.org, †emilio.bueno@uah.es, ${ }^{\dagger}$ rafael.pena-alzola@ strath.ac.uk, ${ }^{\S}$ alberto.rodriguez@imdea.org
}

\begin{abstract}
LCL filters are commonly used to connect Voltage Sourced Converters (VSCs) to the grid. This type of filter is cheaper than a single inductor for the same current THD, but it generates resonance problems if no active or passive damping method is applied. Active damping methods are becoming popular in the literature because they improve efficiency, but they are sometimes difficult to implement and additional measurements are required. This paper proposes an active damping method for VSCs connected to weak grids that is based on making zero the open-loop phase at the resonance frequency. It will be shown that this strategy provides adequate damping of oscillations and that it can be achieved in two different ways: at the design stage (if the design constraints make it possible) or with an allpass filter in series with the current controller. Two methods to design the all-pass filter are proposed. Also, the proposed active damping technique is compared with three alternatives already proposed in the literature. All the control algorithms are verified by simulation and in a $15 \mathrm{~kW}$ prototype of a three-phase VSC connected to a configurable weak grid via a LCL filter.
\end{abstract}

\section{INTRODUCTION}

Voltage Source Converters (VSCs) based on IGBTs are widely used to connect renewable energy sources and other electronic devices to electrical grids [1]. These devices produce high-frequency switching harmonics that must be filtered out to comply with power quality standards like IEC-61000-34 [2] or IEEE-519-2014 [3]. If the connection filter is a single inductor its size is typically large, so the voltage drop becomes excessive and the price increases. A solution to reduce the inductor size is to use a $L C L$ filter because it provides better harmonic attenuation with smaller inductors [4]. However, these filters produce a resonance that commonly interacts with the VSC control system and, therefore, it has to be damped somehow. A solution to damp the resonance is to add a resistor in series with the $L C L$ filter capacitor, and this is commonly known as "passive damping" [4]. Passive damping produce extra losses and reduces the $L C L$ filter performance, but it is a robust solution widely adopted in industry when losses are not of paramount importance. Peña-Alzola et al. [5] propose a formulation to evaluate passive damping losses in grid-connected VSCs and some alternatives to reduce them are described. In a comprehensive approach, Beres et al. [6] propose a design procedure for high-order passive damping filters that makes it possible to minimize losses. However, with this type of solution the number and complexity of the hardware elements increase. When passive damping is not convenient, damping can be provided by the control system, and this commonly known as "active damping" [7].
Multivariable controllers can be used to damp the resonance of $L C L$ filters, but additional voltage and current measurements are required [8,9]. Bao et al. [10] solved this limitation by using an observer and the resulting closed-loop system was robust. In addition, Ochoa et al. [11] propose a Kalman filter to estimate the $L C L$ filter state variables in noisy environments, obtaining accurate estimations. Among multivariable controller alternatives, the "virtual resistor" is commonly applied to emulate the effect of a resistance by using an inner control loop [12]. However, Peña-Alzola et al. [7] revealed that processing and measurements delays reduce the effectiveness of this method and a carefully-designed digital filter has to be added to the control loop. This active damping alternative can applied by measuring the capacitor voltage [7] or current [13]. In addition, Nguyen et al. [9] propose a multi-loop controller that is robust against variations in the $L C L$ filter parameters, which is a common problem in $L C L$ filters. In [14], the resonance of a $L C L$ filter is damped by using a decoupled state-feedback controller. However, with this type of solution it is difficult to figure out which pole position leads to robust performance $[14,15]$. Alternatively, Huerta et al. [16] select the controller gains by using a Linear Quadratic Regulator (LQR), obtaining robust performance in noisy environments. The design of the LQR controller has also been addressed by Ochoa et al. [11], obtaining similar conclusions. As an alternative, Busada et al. [17] propose a high-order controller that makes it possible to choose the closed-loop poles location with a single loop.

Single loop control strategies are popular in the literature since the number of sensors is minimized and, in general, they are easier to design than multivariable controllers. A Posicast controller is a single-loop control alternative that is easy to design and it is placed in series with a classical controller (e.g. PI). This controller alternative was applied by Li et al. [18] to damp the resonance of a current-source converter with a $L C$ filter, giving fast transients. Yao et al. [19] proposed another active damping method based on a nocth filter that is simple, but the design has to be addressed carefully when variations in the grid inductance are expected. In addition, the virtual impedance concept was applied by Wang et al. [20] to control the grid-side current of a $L C L$ filter, providing an adequate damping of the resonance without additional measurements. $\mathrm{Fu}$ and $\mathrm{Li}$ [21] applied neural networks to control the output current of a $L C L$ filter with successful results, but in this case the design is not straightforward and the performance is difficult to predict. Alternatively, Lyu et al. [22] present 


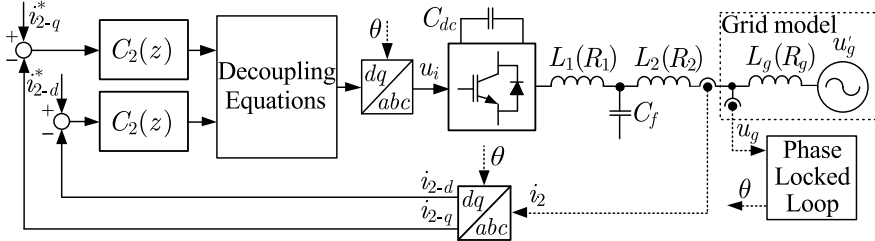

Fig. 1. Electrical diagram of a VSC connected to a weak grid via a $L C L$ filter. The controlled variable is $i_{2}(t)$.

a hysteresis current controller for a VSC with a $L C L$ filter. However, this control technique is difficult to apply in highorder plants like in the $L C L$ filter case.

Recently, the effects of delays in the open-loop transfer function of $L C L$ filters have been studied by Lyu et al. [23], revealing their impact over closed-loop stability. In this sense, Wang et al. [24] explore the effects of these delays taking into account the discrete-time implementation. A similar approach is followed by Chen et al. [25]. The results of these works are promising since they provide a simple solution to damp the resonance with a single control loop.

This paper presents a single-loop control strategy based on all-pass filters to provide active damping to VSCs with $L C L$ filters connected to weak grids. First of all, it will be shown that active damping can be provided at the design stage if the design constraints allow it. However, when this is not possible, an all-pass filter in series with the current controller is used with this purpose. Two alternatives to implement this filter are tested: a first- and a second-order all-pass filter. With this addition a classical PI controller can be easily designed to control the grid-side current of the filter. It will be shown that this strategy provides large stability margins and fast transient responses. The proposed controllers will be compared with three active damping alternatives commonly applied in the literature. All the control system techniques proposed in this paper and the comparative analysis are verified in a $15 \mathrm{kVA}$ prototype of a VSC with a $L C L$ filter. A shorter version of this paper was presented in [26].

\section{Active Damping Overview}

\section{A. Control System Description}

Fig. 1 shows the electrical diagram and the control system of a VSC connected to the grid via a $L C L$ filter. A Synchronous Reference Frame (SRF) $(d q)$ is used to simplify the controller implementation with a Phase Looked Loop (PLL) synchronized with the positive-sequence $d$-axis component of the grid voltage [1]. Therefore, the instantaneous active power $(p(t))$ can be controlled with $i_{2-d}(t)$, while the instantaneous reactive power $(q(t))$ can be controlled with $i_{2-q}(t)$ [1].

\section{B. Modelling Equations}

The transfer function that relates $U_{i}(s)$ with $I_{2}(s)$ for each phase (Laplace transforms of $u_{i}(t)$ and $i_{2}(t)$, respectively) can be written as

$$
P(s)=\frac{b_{1} s+1}{a_{3} s^{3}+a_{2} s^{2}+a_{1} s+a_{0}},
$$

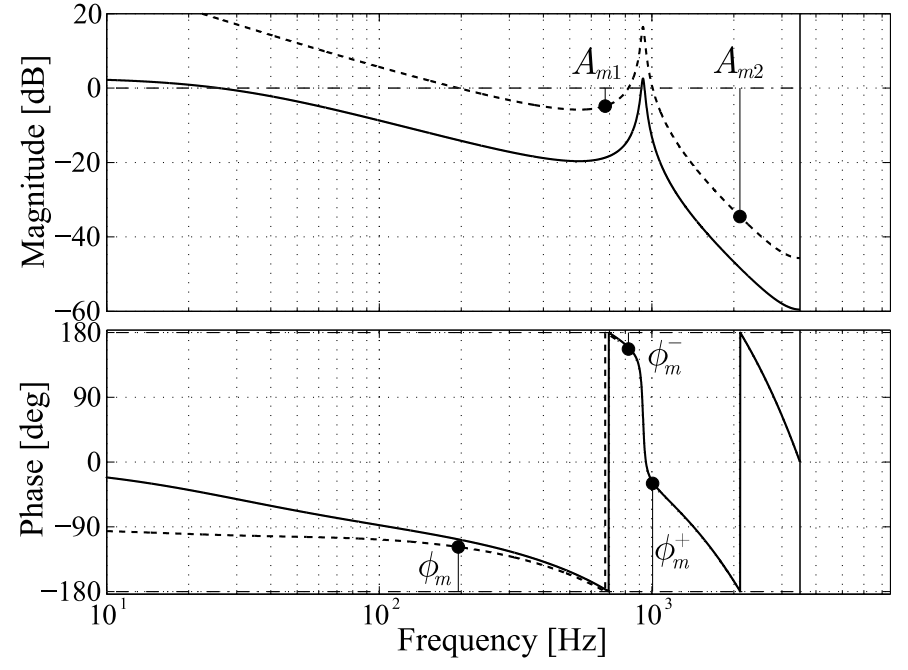

Fig. 2. Frequency response of (solid) $P_{2}(z)$ and (dotted) $G_{2}(z)$, where $C_{2}(z)$ is a PI controller with $\phi_{m}=65 \mathrm{deg}$ (no active damping is used). The sampling frequency is $f_{s}=7 \mathrm{kHz}$.

where

$$
\begin{aligned}
& a_{0}=R_{1}+R_{2}, \\
& a_{1}=L_{1}+L_{2}+C_{f}\left(R_{d} R_{2}^{\prime}+R_{d} R_{1}+R_{1} R_{2}^{\prime}\right), \\
& a_{2}=C_{f}\left(L_{2}^{\prime}\left(R_{d}+R_{1}\right)+L_{1}\left(R_{d}+R_{2}^{\prime}\right)\right), \\
& a_{3}=C_{f} L_{1} L_{2}^{\prime}, \\
& b_{1}=C_{f}\left(R_{d}+R_{2}^{\prime}\right),
\end{aligned}
$$

with $L_{2}^{\prime}=L_{2}+L_{g}$ and $R_{2}^{\prime}=R_{2}+R_{g}$, while $L_{g}$ and $R_{g}$ model the weak grid (inductive grid is assumed). The proposed active damping method is based on frequency-response techniques, so it can be applied even if more advanced grid models are used. The transfer function typically contains a low-frequency pole, a pair of high-frequency complex poles, and a highfrequency zero. The complex poles resonance frequency is [4]:

$$
\omega_{r}=\sqrt{\frac{1}{C_{f}} \frac{L_{2}^{\prime}+L_{1}}{L_{2}^{\prime} L_{1}}} .
$$

The plant in (1) can be discretized with the Zero Order Hold $(\mathrm{ZOH})$ method, together with a number of processing and measurements delays $(n)$, yielding:

$$
P_{2}(z)=z^{-n} Z\{P(s)\}_{Z O H},
$$

where $z$ is the discrete-time Laplace variable [27].

\section{Classical Current Controller with LCL Filters}

A PI controller can be used to track constant set-points of $i_{2-d}$ and $i_{2-q}$ if the grid voltage is balanced [1]. Therefore:

$$
C_{2}(z)=K_{p}+K_{i} \cdot z /(z-1),
$$

where $K_{p}$ and $K_{i}$ are the proportional and integral gains, respectively. Fig. 2 shows the Bode plot of $P_{2}(z)$ and $G_{2}(z)=P_{2}(z) C_{2}(z)$, where $C_{2}(z)$ is a PI controller designed with a phase margin $\left(\phi_{m}\right)$ of 65 degrees, while $t_{s}$ is the sampling period $\left(f_{s}=1 / t_{s}\right.$ is the sampling frequency). The system parameters are defined in Section VII-B. The phase of 


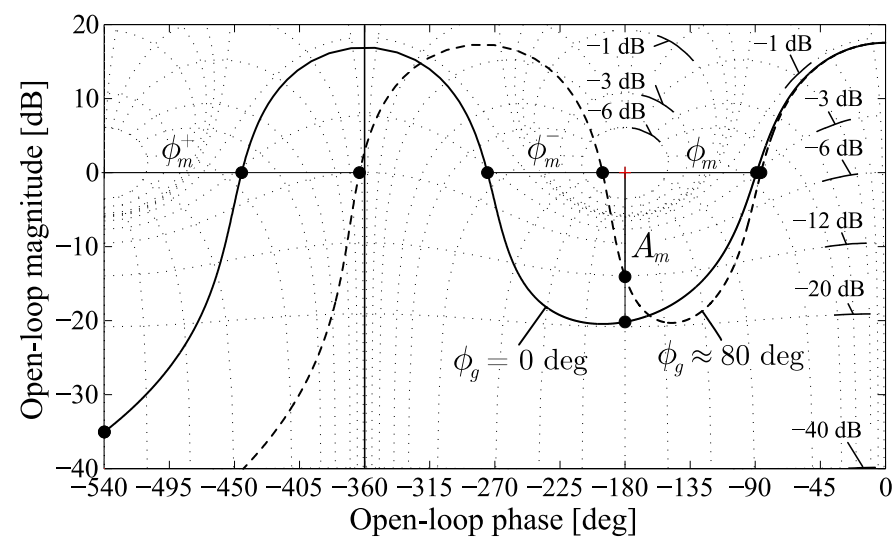

Fig. 3. Nichols chart of $P\left(e^{j \omega t_{s}}\right)$, when (solid) $\phi_{g} \approx 80 \mathrm{deg}$, and when (dashed) $\phi_{g} \approx 0 \mathrm{deg}$. Phase margins are $\phi_{m}, \phi_{m}^{+}$, and $\phi_{m}^{-}$, while the gain margin is $A_{m}$.

$G_{2}(z)$ is hardly modified at high frequency and the system is not well damped. Therefore, it is clear that the damping problem cannot be solved with this type of controller since a PI controller has almost no effect at the resonance frequency.

\section{Proposed Active Damping Solution}

The core of the active damping method proposed in this paper is to guarantee zero phase at the resonance frequency. This condition can be written as

$$
G_{2}\left(e^{j \omega_{r} t_{s}}\right)=A_{g} e^{j \phi_{g}}, \text { with } \phi_{g}=0 \mathrm{deg} .
$$

Fig. 3 shows the open-loop Nichols chart of $P_{2}\left(e^{j \omega t_{s}}\right)$, for two different cases. For the first case $\phi_{g} \approx 80 \mathrm{deg}$, while for the second case $\phi_{g}=0$ deg (remember that $\phi_{g} \approx \phi_{p}$ ). When $\phi_{g} \approx 80 \mathrm{deg}$, one phase margin $\left(\phi_{m}^{-}\right)$is small, while the other one $\left(\phi_{m}^{+}\right)$is large. However, for $\phi_{g}=0$ deg the phase margins are almost equal $\left(\phi_{m}^{+} \approx-\phi_{m}^{-}\right)$. This means that the phase margins are (approximately) maximum since any additional change in $\phi_{g}$ (either positive or negative) will worsen either $\phi_{m}^{+}$or $\phi_{m}^{-}$. Therefore, the fulfilment of $\phi_{g}=0 \mathrm{deg}$ will produce controllers with large stability margins.

In this paper, two alternatives to achieve $\phi_{g}=0$ are explored:

1) Active Damping at the Design Stage: With this method the resonance frequency $\left(\omega_{r}\right)$ or the sampling period $\left(t_{s}\right)$ are modified to achieve $\phi_{g}=0$ deg without any control system addition.

2) Active Damping with All-Pass Filters: If active damping cannot be provided at the design stage (e.g. $\omega_{r}$ and $t_{s}$ cannot be modified due to design constraints), a unitary-gain digital all-pass filter [28], called $D(z)$, is proposed to achieve $\phi_{g}=0$ deg. From Fig. 4,

$$
G_{2}(z)=C_{2}(z) D(z) P_{2}(z) .
$$

The frequency response of (7) at the resonance frequency is:

$$
G_{2}\left(e^{j \omega_{r} t_{s}}\right)=\underbrace{\left(A_{c} e^{j \phi_{c}}\right)}_{C_{2}\left(e^{j \omega_{r} t_{s}}\right)} \cdot \underbrace{\left(e^{j \phi_{d}}\right)}_{D\left(e^{j \omega_{r} t_{s}}\right)} \cdot \underbrace{\left(A_{p} e^{j \phi_{p}}\right)}_{P_{2}\left(e^{j \omega_{r} t_{s}}\right)} .
$$

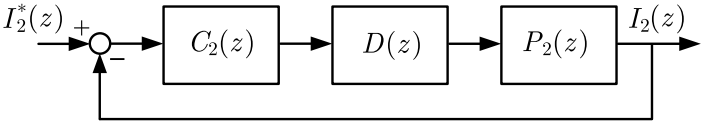

Fig. 4. Equivalent control diagram of the controlled plant (only one axis), including $D(z)$.

The all-pass filter structure of $D(z)$ provides unitary gain in the whole frequency range. Therefore, $\left|D\left(e^{j \omega t_{s}}\right)\right|=1 \forall \omega$. Meanwhile, the filter coefficients will be designed so that $\phi_{g}=0 \mathrm{deg}$. This condition can be written as follows

$$
\phi_{g}=\phi_{c}+\phi_{d}+\phi_{p}=0 .
$$

Therefore, $\phi_{d}$ (the phase introduced by the all-pass filter) should be chosen so that (9) is satisfied. As $D(z)$ is an allpass filter, $\left|D\left(e^{j \omega t_{s}}\right)\right|=1 \forall \omega$ and high-frequency noise is not amplified. This feature also simplifies the design of the current controller since the original module of $P_{2}(z)$ is not modified (only the phase).

Two versions of the filter $D(z)$ are explored in this paper. The first alternative is a first-order all-pass filter, while the second one is a second-order all-pass filter. It will be shown that:

1) A first-order all-pass filter provides adequate damping of oscillations and is robust against grid inductance variations. However, it slightly slows down the transient response.

2) A second-order all-pass filter is proposed as an alternative solution to make the transient response faster. However, it will be shown that this alternative slightly reduces the system robustness against grid inductance variations.

Finally, the proposed active damping method is compared with three popular active damping alternatives already proposed in the literature.

\section{E. Robustness Against Grid Inductance $\left(L_{g}\right)$ Variations}

The closed-loop system robustness against $L_{g}$ variations can be quantified with:

$$
\left|\frac{d \phi_{g}}{d L_{g}}\right|=\left|\frac{d\left(\phi_{c}+\phi_{d}+\phi_{p}\right)}{d L_{g}}\right| \approx\left|\frac{d\left(\phi_{d}+\phi_{p}\right)}{d L_{g}}\right|,
$$

assuming that $\phi_{c} \approx 0 \mathrm{deg}$. The lower the value of $\left|d \phi_{g} / d L_{g}\right|$ is, the less sensitive $\phi_{g}$ is to changes in the resonance frequency. This means that the damping condition will be less affected by changes in $L_{g}$. It will be shown that $d \phi_{g} / d L_{g}$ can be modified when $D(z)$ is designed. However, if widespread variations of $L_{g}$ are expected, a zero-pole study may be more appropriate than minimizing $\left|d \phi_{g} / d L_{g}\right|$.

\section{Active Damping at the Design Stage}

As shown before, at the resonance frequency $\phi_{c} \approx 0$, so $\phi_{g} \approx \phi_{p}$. The value of $\phi_{p}$ can be estimated by analysing the poles and zeros of $P_{2}(z)$. First of all, the low-frequency pole contribution to $\phi_{g}$ is almost $-90 \mathrm{deg}$. Secondly, the resonant poles provide almost no phase until their resonance frequency 
is reached, when the phase suffers a -180 deg phase shift centred at $\omega_{r}$. Finally, the phase introduced by the delays is $-n \omega_{r} t_{s}$ rad, while the high-frequency zero has almost no contribution to the phase at $\omega_{r}$. Taking into account all the considerations above, the condition that makes $\phi_{g}=0 \mathrm{deg}$ can be approximately written as:

$$
\exists k \in \mathbb{N}: \phi_{p} \approx-n \omega_{r} t_{s}-\pi=2 k \pi .
$$

It can be seen that there are two alternatives to fulfil (11), which are to modify a) $\omega_{r}$ or b) $t_{s}$. However, design constraints can limit the applicability of this strategy since these parameters are generally set by the application. Clearly, the simplified formula in (11) can be replaced by the actual value of $\phi_{p}$ calculated with $P_{2}\left(e^{j \omega_{r} t_{s}}\right)$, but (11) provides valuable information to understand the damping problem.

\section{Active Damping Based on All-Pass Filters}

If active damping cannot be provided at the design stage due to design constraints, and all-pass filter in series with the current controller is proposed in this section. Two methods to design this filter are proposed.

\section{A. Alternative 1: First-Order All-Pass Filter}

The simplest alternative for $D(z)$ is a first-order digital allpass filter $[28,29]$ :

$$
D^{\prime}(z)=\frac{\left(1+d^{\prime}\right) z^{-1}+\left(1-d^{\prime}\right)}{\left(1-d^{\prime}\right) z^{-1}+\left(1+d^{\prime}\right)},
$$

where $d^{\prime} \in(0,1)$ can be modified to adjust the filter phase at the resonance frequency. If $d^{\prime} \notin(0,1)$, the filter is unstable. The phase of $D^{\prime}\left(e^{j \omega t_{s}}\right)$ at $\omega_{r}$ is [29]:

$$
\phi_{d}^{\prime}=2 \arctan \left(\frac{\left(1-d^{\prime}\right) \sin \left(\omega_{r} t_{s}\right)}{\left(1+d^{\prime}\right)+\left(1-d^{\prime}\right) \cos \left(\omega_{r} t_{s}\right)}\right)-\omega_{r} t_{s} .
$$

Fig. 5 shows the phase of $D^{\prime}\left(e^{j \omega t_{s}}\right)\left(f_{s}=10 \mathrm{kHz}\right)$ for $d^{\prime} \in(0,1)$. The phase for a given resonance frequency $\omega_{r}$ ( $f_{r}$ in Hertz) can be modified by changing $d^{\prime}$. Therefore, the value that gives $\phi_{d}^{\prime}$ can be solved from (13), yielding

$$
d^{\prime}=\tan \left(\phi_{d}^{\prime} / 2\right) / \tan \left(\omega_{r} t_{s} / 2\right) \text {. }
$$

As shown in Fig. $5, D^{\prime}(z)$ cannot provide any phase value between 0 and $360 \mathrm{deg}$. Therefore, if more phase is required, a higher-order all-pass filter can be used instead [29]. A simple solution is to use $m$ filters like (12) in series, thus

$$
D(z)=\left(D^{\prime}(z)\right)^{m} .
$$

Now, $\phi_{d}$ can be divided between these $m$ filters, yielding

$$
\phi_{d}^{\prime}=\phi_{d} / m \text {. }
$$

The minimum and maximum phase that each of these filters is able to provide can be calculated from (14) by making $d^{\prime}=0$ and $d^{\prime}=1$, respectively:

$$
0<\phi_{d}^{\prime}<\omega_{r} t_{s} .
$$

In order to calculate the number of $D^{\prime}(z)$ filters required to provide $\phi_{d}$, (16) and (17) can be merged, yielding

$$
m \geq \phi_{d} /\left(\omega_{r} t_{s}\right) \in \mathbb{N} .
$$

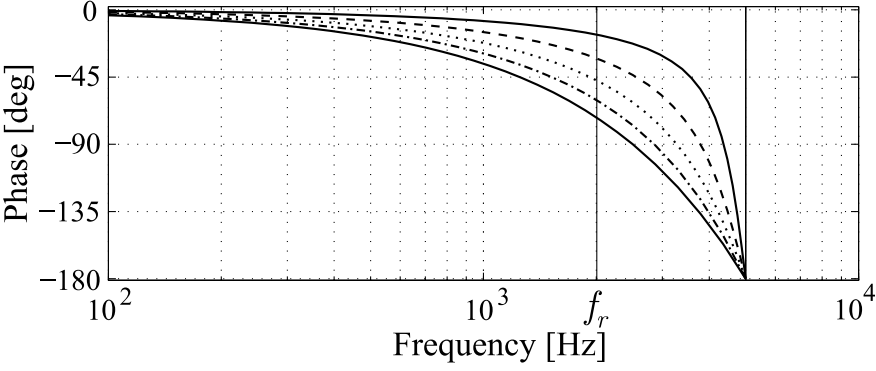

Fig. 5. Phase introduced by $D^{\prime}\left(e^{j \omega t_{s}}\right)$, for different values of $d^{\prime}$. From top to bottom, $d^{\prime}=0.1,0.3,0.5,0.7$, and $0.9\left(f_{s}=10 \mathrm{kHz}\right)$.

The main drawback of this method is that the phase introduced at low frequency can significantly slow down the transient response.

\section{B. Alternative 2: Second-Order All-Pass Filter}

If the transient response obtained with the first-order allpass filter in (12) is not fast enough, the latter can be replaced by a $h$ th-order all-pass filter. This filter can be used not only to guarantee that $\phi_{g}=0$ but also to set the phase at other frequencies. This additional degree of freedom is used here to improve the transient response.

A $h$ th-order all-pass filter can be defined as follows:

$$
D^{\prime}(z)=\frac{\sum_{k=0}^{h} a_{k} z^{k-h}}{\sum_{k=0}^{h} a_{k} z^{-k}},
$$

where $a_{k}$ are the filter coefficients and $k$ is an auxiliary index. If $a_{0}=1$ in (19), the filter has unitary gain. The phase response of this filter is [29]:

$$
\phi^{\prime}=-h \omega t_{s}+2 \arctan \left(\frac{\sum_{k=0}^{h} a_{k} \sin \left(k \omega t_{s}\right)}{\sum_{k=0}^{h} a_{k} \cos \left(k \omega t_{s}\right)}\right),
$$

where $\phi^{\prime}$ is the phase introduced by (19) at any given frequency $(\omega)$. This expression can be rewritten as follows

$$
\sum_{k=0}^{h} a_{k}\left[\tan \left(\frac{\phi^{\prime}+h \omega t_{s}}{2}\right) \cos \left(k \omega t_{s}\right)-\sin \left(k \omega t_{s}\right)\right]=0 .
$$

This result can be used to adjust the phase of $h$ frequencyresponse points $\left(\phi_{1}\right.$ at $\omega_{1}, \phi_{2}$ at $\omega_{2}$, etc.). Together with $a_{0}=1$, this yields a set of $h+1$ linear equations:

$$
A \cdot\left[\begin{array}{lllll}
a_{0} & a_{1} & \ldots & a_{h-1} & a_{h}
\end{array}\right]^{\prime}=B,
$$

where $A$ is a $(h+1) \times(h+1)$ matrix, while $B$ is $(h+1) \times 1$ matrix. This system of equations is linear. Therefore, it can be solved as follows:

$$
\left[\begin{array}{lllll}
a_{0} & a_{1} & \ldots & a_{h-1} & a_{h}
\end{array}\right]^{\prime}=A^{-1} B .
$$




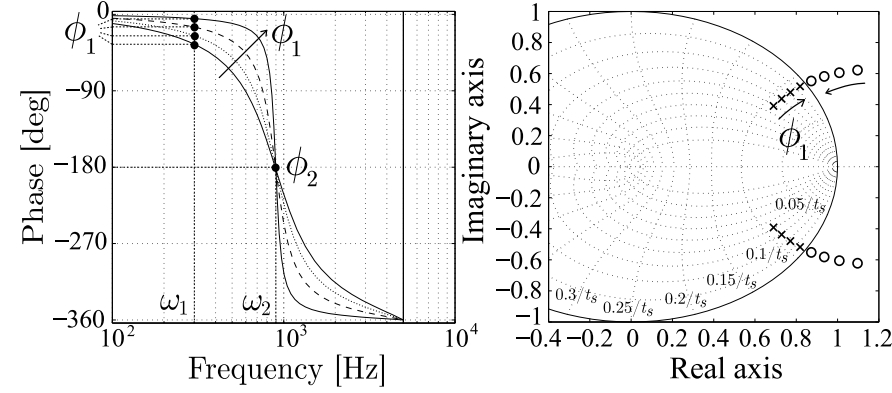

Fig. 6. (left) Phase response of $D^{\prime}(z)$ designed with two points $\left(\phi_{1}\right.$ for $\omega_{1}$ and $\phi_{2}$ for $\omega_{2}$ ). The value of $\phi_{2}$ is $-180 \mathrm{deg}$, while $\phi_{1}=-10,-20,-30$, and -40 deg. (right) Pole-zero map of $D^{\prime}(z)$ for the aforementioned cases.

This design method can give an unstable filter if the points are not chosen carefully, so one must verify that $D^{\prime}(z)$ is stable. A possible solution is to use a single high-order filter that adjusts $h$ points. Unfortunately, it has been found difficult to find a set of frequency-response points that leads to a stable filter when $h>2$. To avoid this situation, a second-order filter is chosen to adjust $\phi_{1}$ at $\omega_{1}$ and $\phi_{2}$ at $\omega_{2}$. Therefore, the point 2 is used to compensate $\phi_{p}$ at $\omega_{r}$, while the point 1 is used to improve the transient response. The phases $\phi_{1}$ and $\phi_{2}$ can be provided by $m$ filters, therefore:

$$
\phi_{1}^{\prime}=\phi_{1} /(2 m) \text { and } \phi_{2}^{\prime}=\phi_{2} /(2 m) \text {. }
$$

A first approximation for $m$ can be obtained with the firstorder filter formulas. Therefore:

$$
m \geq \max \left\{\phi_{1} /\left(2 \omega_{1} t_{s}\right), \phi_{2} /\left(2 \omega_{2} t_{s}\right)\right\} \in \mathbb{N},
$$

although the validity of this result must be verified when the coefficients are computed. Fig. 6 shows the frequency response of $D^{\prime}(z)$, where $\phi_{2}=-180 \mathrm{deg}$ for $\omega_{2}=900 \cdot 2 \pi \mathrm{rad} / \mathrm{s}$, and $\omega_{1}=300 \cdot 2 \pi \mathrm{rad} / \mathrm{s}$ for $\phi_{1}=-10,-20,-30$, and $-40 \mathrm{deg}$ $\left(f_{s}=10 \mathrm{kHz}\right)$. The filters are stable and provide the required phase at $\omega_{1}$ and $\omega_{2}$.

\section{Practical Active Damping Guide}

The concepts explained in Section III and IV have been organised in a guide so that the proposed active damping method can be easily applied:

1) If possible, design the converter to guarantee that $\phi_{p}=0 \mathrm{deg}\left(\right.$ or $\phi_{g}=0$ ). If this condition is met, active damping is provided at the design stage. This means that $D(z)$ is not necessary and a classical PI controller is enough to control the output current.

2) If $\phi_{p}$ differs to a great extend from zero, try the firstorder all-pass filter to fulfil $\phi_{g}=0 \mathrm{deg}$ :

a) First, use (18) to calculate the number of $D^{\prime}(z)$ filters $(m)$ required to guarantee that $\phi_{d}=-\phi_{p}$.

b) Use (14) to calculate the parameter of the firstorder all-pass filter $\left(d^{\prime}\right)$.

c) Use a PI controller for $C_{2}(z)$, and design it by using any classical method, but taking into account that $D(z)$ is in series with $P_{2}(z)$. In this paper, the design will be carried out by setting the open-loop phase margin $\left(\phi_{m}\right)$ and crossover frequency $\left(\omega_{c}\right)$.

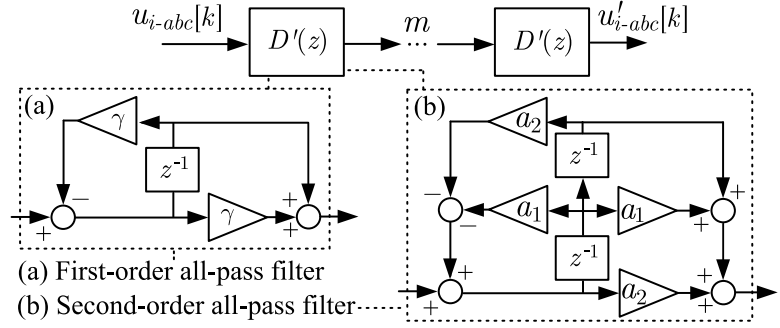

Fig. 7. Implementation of (a) a first- and (b) a second-order all-pass filter. The structure is similar for each phase $(a b c)$. For the first-order all-pass filter: $\gamma=\left(1-d^{\prime}\right) /\left(1+d^{\prime}\right)$.

3) If bandwidth (or transient response) does not fulfil the specifications, try a high-order all-pass filter:

a) Select the frequency response points to design $D(z)$. Try with $\phi_{2}=-\phi_{p}$ at $\omega_{2}=\omega_{r}$ for the first point, and choose $\phi_{1}$ at the desired crossover frequency $\left(\omega_{1}=\omega_{c}\right)$ (e.g. $\left.-15 \leq \phi_{1} \leq 0 \mathrm{deg}\right)$ for the second point. The closer the value of $\phi_{1}$ is to zero, the faster the closed-loop system would be.

b) Obtain the filter coefficients by solving (22) and verify that $D(z)$ is stable.

c) Use a PI controller for $C_{2}(z)$ and design it by using any classical method, but taking into account that $D(z)$ is in series with $P_{2}(z)$.

4) If the design does not fulfil the requirements, modify the frequency response points used to design $D(z)$.

It is worth pointing out that in this paper $D(z)$ is not changed during operation. However, it is easy to see that it can be adapted in real time if the grid impedance is estimated.

The proposed active damping solutions have been implemented as shown in Fig. 7. The filters are implemented in $a b c$ coordinates.

\section{Vi. Alternative Active Damping Solutions}

This section describes three active damping alternatives that will be compared with the one proposed in this paper: a notch filter, a virtual resistor, and a LQR controller.

\section{A. Comparative Alternative 1: Notch Filter}

Notch filters have been proposed by several authors to solve the damping problem $[19,30]$. These filters are easy to design and no additional measurements are required to damp the resonance [30]. The block diagram in this case is similar to that in Fig. 4, but $D(z)$ has to be replaced by a notch filter, called $N(z)$, that is defined as follows:

$$
N(z)=\frac{1+\rho^{2}}{2} \frac{z^{2}-2 \cos \left(\omega_{n} t_{s}\right) z+1}{z^{2}-\left(1+\rho^{2}\right) \cos \left(\omega_{n} t_{s}\right) z+\rho^{2}},
$$

where $\omega_{n}$ is the notch frequency and $\rho \in(0,1)$ is a parameter used to adjust the filter narrowness. The gain $\left(1+\rho^{2}\right) / 2$ provides unitary DC gain so that low-frequency dynamics are not modified. Other formulations of this filter are also possible [19]. Typically, the notch frequency of the filter is selected to cancel out the resonance frequency of the $L C L$ filter, as shown in Fig 8 (green). However, if the grid inductance 


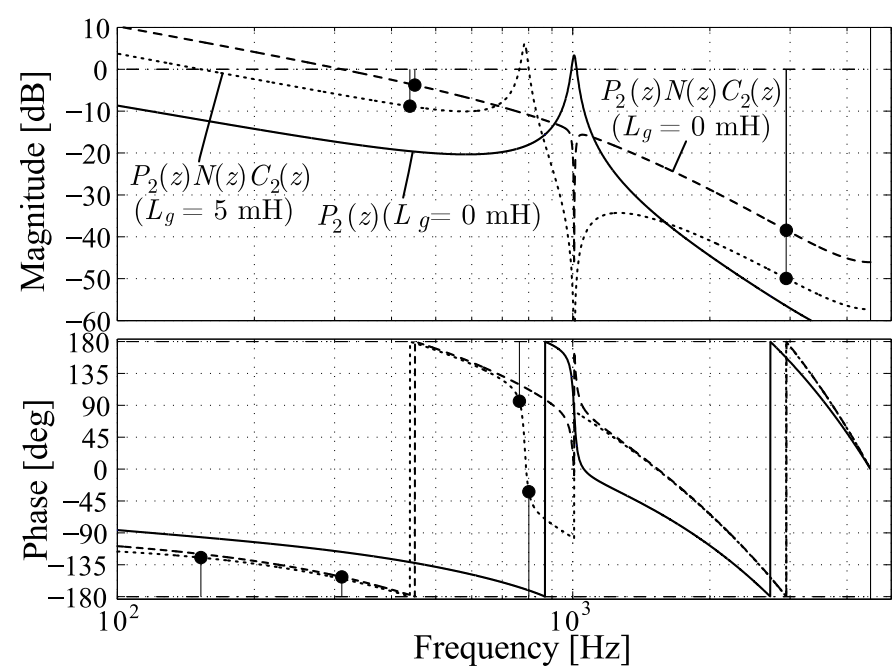

Fig. 8. Bode diagram of (solid) $P_{2}(z)$, and $G_{2}(z)=P_{2}(z) N(z) C_{2}(z)$ for (dashed) $L_{g}=0 \mathrm{mH}$ and (dotted) $L_{g}=5 \mathrm{mH}$.

changes, the notch filter will not be tuned at the resonance frequency and this can potentially lead to instability [19]. Fig. 8 (red) shows that, when $L_{g}=5 \mathrm{mH}$ (weak grid), the resonance peak is not cancelled. Anyway, the closed-loop system is stable, but this effect is due to open-loop phase value at the resonance frequency (not because of the reduction in the module). Therefore, for weak grids the value of $\omega_{n}$ and $\rho$ should be selected so that the closed-loop system remains stable regardless the value of $L_{g}$ [19].

Like in the all-pass filter alternative, the notch filter can be adapted in real time if the resonance frequency is identified. However, to make a fair comparison, this feature has not been applied here (adaptive controllers are not studied in this paper).

\section{B. Comparative Alternative 2: Virtual Resistor}

With this alternative, the current through the filter capacitor $\left(i_{c}\right)$ is multiplied by a virtual resistor $\left(R_{v}\right)$ in order to emulate (virtually) the effect of a resistor in series with the capacitor [7, 31]. To achieve this goal, the following term is added to the original command $\left(\vec{u}_{i}\right)$ :

$$
\Delta \vec{u}_{i}=-R_{v} \vec{i}_{c}=-R_{v}\left(\vec{i}_{1}-\vec{i}_{2}\right) .
$$

This method can give accurate results if the sampling period is fast enough. However, digital implementation delays limit the direct application of this method and a phase compensator is commonly added to solve this issue [7]. The virtual resistor with the compensator can be written as follows

$$
R_{v}(z)=R_{v}^{\prime} \frac{\alpha_{1} z+\alpha_{0}}{\beta_{1} z+\beta_{0}},
$$

where $R_{v}^{\prime}$ is the effective value of the virtual resistor, while $\alpha_{0}, \alpha_{1}, \beta_{0}$, and $\beta_{1}$ are the compensator parameters that can be obtained as suggested by Peña-Alzola $e t$ al. [7].

\section{Comparative Alternative 3: Multivariable LQR Controller}

With this alternative, a state-feedback controller that includes all the system state variables is applied. The closedloop pole position is selected by solving the $L Q R$ problem in order to obtain a robust controller [32]. The LQR design methodology produces very robust controllers, so it is an appropriate choice to control VSCs connected to weak grids. In this paper, the control problem is posed in discrete by using a complete state-space model of the system. Therefore, the cross-coupling terms and the delays are included in the optimization problem $[11,33]$.

The command signal of the VSC with a state-feedback (LQR) controller is

$$
\mathbf{U}_{i}[k]=-\mathrm{K}_{o p t} \cdot \mathbf{X}_{e}[k],
$$

where $\mathbf{X}_{e}[k]$ is the extended version of the state variable vector, which includes the state variables of the $L C L$ filter (in $d q$ ), two delays in the command signals, and an integral controller for the current of each axis $[11,14,33]$. The command signal of the power converter is $\mathbf{U}_{i}[k]$. The gain of the controller is $\mathrm{K}_{\text {opt }}$ and its value is obtained by minimizing the following index

$$
J=\sum_{k=1}^{\infty} \mathbf{X}_{e}^{\mathrm{T}}[k] \mathbf{Q} \mathbf{X}_{e}[k]+\mathbf{U}_{i}^{\mathrm{T}}[k] \mathbf{R} \mathbf{U}_{i}[k],
$$

where superscript $\mathrm{T}$ means transposed, while $\mathbf{Q}$ and $\mathbf{R}$ are weighting matrices that are used to design the controller. Detailed information of the design procedure can be found in $[11,16]$. For the scope of this paper, it is worth pointing out that robustness is against transient performance. Therefore, to perform a fair comparison, the transient speed has been made similar to the other alternatives.

\section{CAse Study}

\section{A. System Description}

The nominal grid conditions are $400 \mathrm{~V}$ RMS (phase-tophase) and $50 \mathrm{~Hz}$. The $L C L$ filter parameters are $L_{1}=2.3 \mathrm{mH}$ $\left(R_{1}=70 \mathrm{~m} \Omega\right), L_{2}=0.93 \mathrm{mH}\left(R_{2}=30 \mathrm{~m} \Omega\right)$, and $C_{f}=23.8 \mu \mathrm{F}\left(R_{d}=0 \mathrm{~m} \Omega\right)$. An additional transformer with $1 \mathrm{mH}$ leakage inductance is used to connect the VSC to the grid. Therefore, $f_{r}=1.27 \mathrm{kHz}$ without the transformer, and $f_{r}=1.0 \mathrm{kHz}$ with it. Weak grid conditions are emulated inserting inductances between the grid and the $L C L$ filter. Therefore, $L_{g}$ can be varied from 0 to $5 \mathrm{mH}$ (plus the connection transformer).

Two designs has been carried out in order to highlight the contributions of this paper:

1) Damping is achieved at the design stage.

2) Damping is achieved with a) a first- and b) a secondorder all-pass filter.

Finally, the robustness of the control system alternatives against $L_{g}$ variations is compared.

\section{B. Prototype Description}

The proposed control system has been tested in the Smart Energy Integration Lab (SEIL) [34,35]. The DC-link voltage is maintained constant with an additional rectifier. The sampling $\left(f_{s}\right)$ and switching $\left(f_{s w}\right)$ frequencies are equal and can be varied from $5 \mathrm{kHz}$ to $20 \mathrm{kHz}$. Pulse Width Modulation (PWM) with third harmonic injection is used [1]. The control system is implemented in a embedded PC [34]. The controller has 


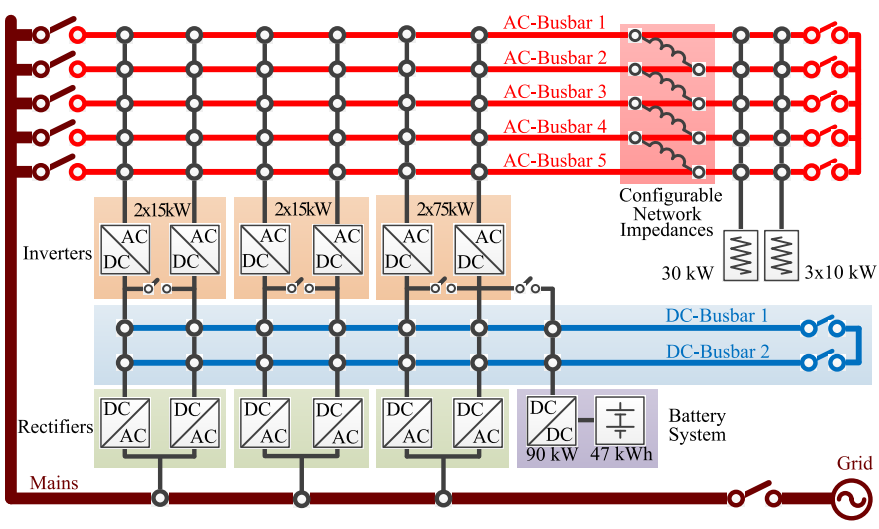

Fig. 9. Electrical diagram of the Smart Energy Integration Lab (SEIL). White circles indicate electromechanical switches used to configure the grid.

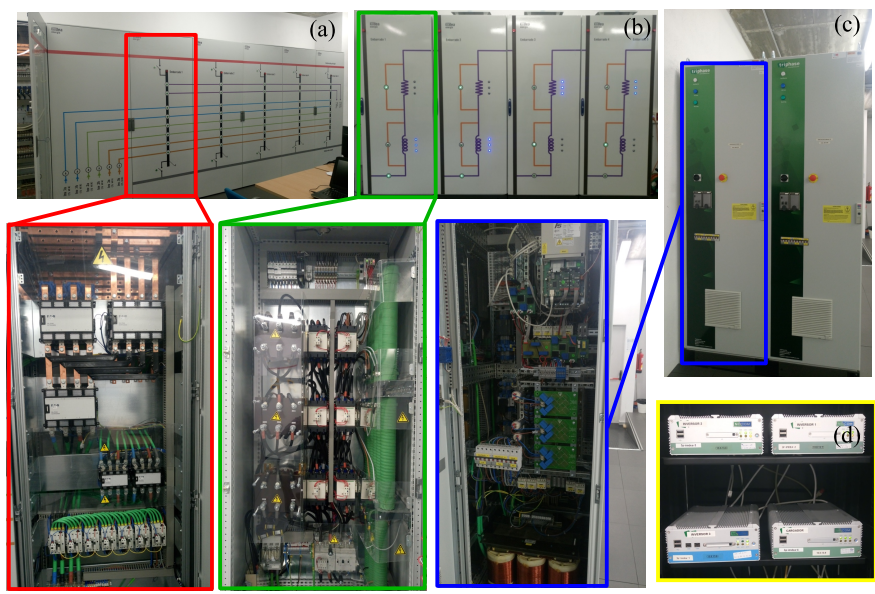

Fig. 10. SEIL Photograph. (a) AC electrical grid, (b) configurable network impedances, (c) power converter, and (d) embedded PCs.

two inherent delays $(n=2)$, one due to computations and another due to measurements. Decoupling equations are used to control the $d q$-axis dynamics, independently [36].

Fig. 9 shows the hardware diagram of the laboratory. The VSC1 is connected to the AC busbar 1 . The busbars 2, 3, and 4 are used to introduce the network impedances, while the busbar 5 is connected to the grid. An additional rectifier is used to maintain the DC voltage constant. Fig. 10 shows a photograph of the SEIL, including the details of electrical cabinets. The network impedances are connected between buses by using electromechanical switches. This makes it possible to emulate weak grid conditions. The power converters are connected to the busbars via $L C L$ filters and coupling transformers.

\section{Simulator Description}

A simulator has been developed by using Matlab and Simulink, with its SimPowerSystems Toolbox. The electric power system and the VSC are simulated with SimPowerSystems. Meanwhile, the control system is implemented in Simulink by using the $z$-transform. A finite state machine is used to manage the connection and disconnection to the grid. For the real-time implementation, the control algorithm developed in Simulink is directly downloaded to the embedded PCs by using an automatic code generation tool. Therefore, there

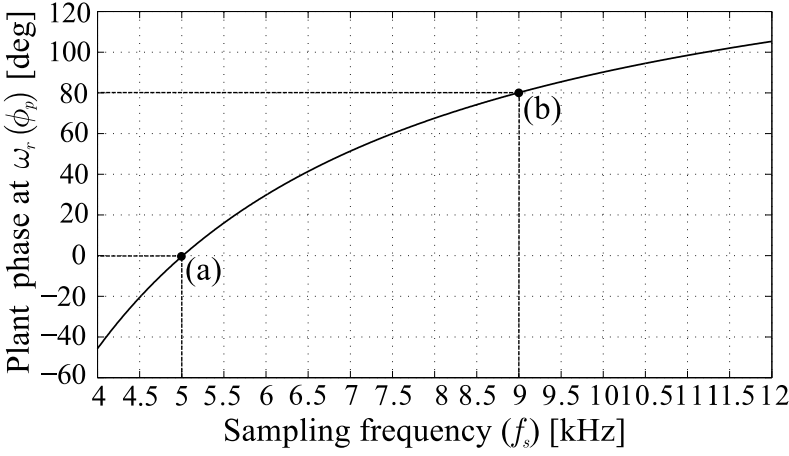

Fig. 11. Plant phase at the resonance frequency $\left(\phi_{p}\right)$ changing the sampling frequency $\left(f_{s}\right)$. Cases studied: (a) $\phi_{p}=0 \mathrm{deg}$ and (b) $\phi_{p} \approx 80 \mathrm{deg}$.

are no differences between the control algorithms used for the simulations and the experiments (apart from implementation effects such as quantization, etc.).

\section{Achieving Damping at the Design Stage}

Since the $L C L$ filter values and $n$ have been already set, only $t_{s}$ can be modified to provide active damping at the design stage. This situation is not common in industry since $t_{s}$ is generally set by the application, but it is explored here for demonstration purposes only. Fig. 11 shows $\phi_{p}$ when $f_{s}$ changes. For $f_{s} \approx 5 \mathrm{kHz}, \phi_{p} \approx 0$ deg. Fig. 12 shows the frequency response of $P_{2}(z)$ and $G_{2}(z)$ when $f_{s}=5 \mathrm{kHz}$. The controller $C_{2}(z)$ has been calculated with $\phi_{m}=45 \mathrm{deg}$ and implemented as shown in (5). The phase of $C_{2}(z)$ at $\omega_{r}$ is $\phi_{c}=-1 \mathrm{deg}$, so it hardly affects $\phi_{m}^{+}$and $\phi_{m}^{-}$. The phase margins are $\phi_{m}=45 \mathrm{deg}, \phi_{m}^{-}=-78.4 \mathrm{deg}$, and $\phi_{m}^{+}=77.1 \mathrm{deg}$, while $A_{m 1}=7 \mathrm{~dB}$ and $A_{m 2}=22 \mathrm{~dB}$.

The oscillating frequency $\left(\omega_{u}\right)$ of the plant is $500 \mathrm{~Hz}$, approximately, and it is slightly affected when $C_{2}(z)$ is applied.

\section{ViII. Controller Design and Simulation Results}

\section{A. Active Damping with First-Order All-Pass Filters}

Fig. 13 shows the frequency response of $P_{2}(z)$ and $G_{2}(z)$ when $f_{s}=9 \mathrm{kHz}$ and $D(z)$ compensates the plant phase at the resonance frequency $\left(\phi_{p}\right)$. The value of $\phi_{p}$ is $80.95 \mathrm{deg}$, so $D(z)$ is necessary. The minimum number of $D^{\prime}(z)$ filters is calculated with (18), yielding $m=3$. Therefore, $D(z)$ is designed to provide $\phi_{d}=-\phi_{p}$, giving $d^{\prime}=0.65$. The controller $C_{2}(z)$ is calculated in continuous time with $\phi_{m}=45 \mathrm{deg}$. The phase margins are $\phi_{m}=45 \mathrm{deg}, \phi_{m}^{-}=-77.5 \mathrm{deg}$, and $\phi_{m}^{+}=76.3 \mathrm{deg}$, while the gain margins are $A_{m 1}=7.2 \mathrm{~dB}$, $A_{m 2}=21 \mathrm{~dB}$, and $A_{m 3}=44 \mathrm{~dB}$.

The oscillating frequency $\left(\omega_{u}\right)$ is approximately $850 \mathrm{~Hz}$, and it is reduced to $500 \mathrm{~Hz}$ when $D(z)$ and $C_{2}(z)$ are applied.

\section{B. Active Damping with Second-Order All-Pass Filters}

In this case, $D(z)$ is designed to improve the transient response. Therefore, $\omega_{1}=200 \cdot 2 \pi \mathrm{rad} / \mathrm{s}$ (cross-over frequency, approximately) and $\phi_{1}=-5,-10$, and $-15 \mathrm{deg}$, while $\omega_{2}=\omega_{r}$ for $\phi_{2}=-\phi_{p}$. The number of filters $(m)$ is 1 . The 


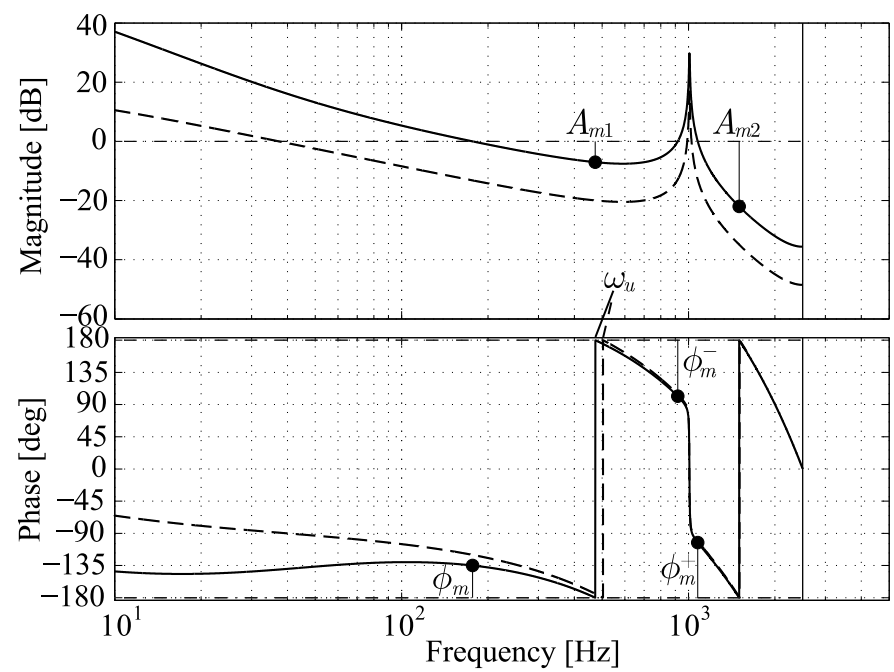

Fig. 12. Open-loop frequency response of (dotted) $P_{2}(z)$ and (dashed) $G_{2}(z)$ when damping is provided at the design stage $\left(f_{s}=5 \mathrm{kHz}\right)$.

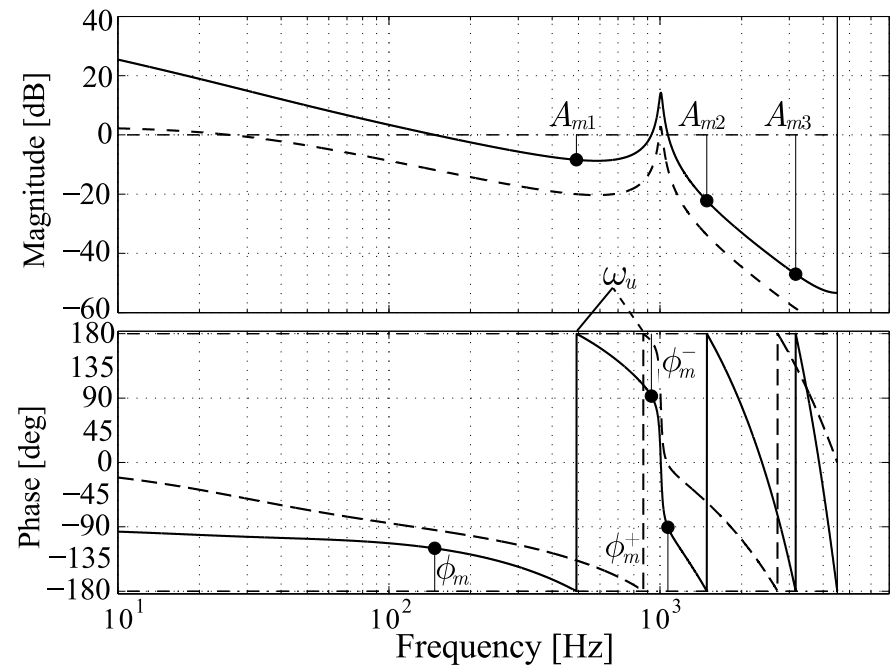

Fig. 13. Frequency response of (dotted) $P_{2}(z)\left(f_{s}=9 \mathrm{kHz}\right)$ and (solid) $G_{2}(z)$, with a first-order all-pass filter.

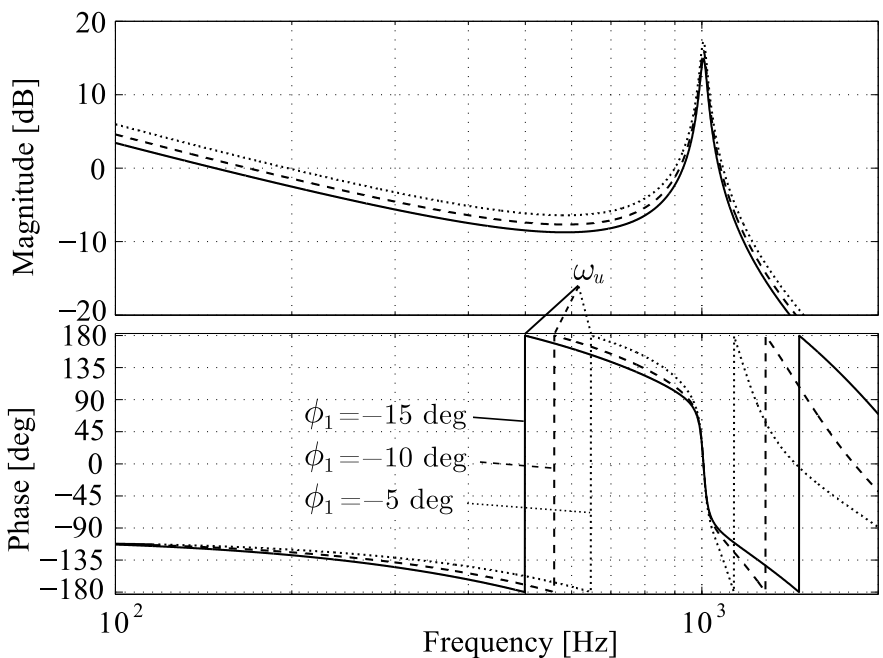

Fig. 14. Frequency response of $G_{2}(z)\left(f_{s}=9 \mathrm{kHz}\right)$, when $D(z)$ is a secondorder all-pass filter and $C_{2}(z)$ is PI controller. The value of $\phi_{1}$ is $-5,-10$, and $-15 \mathrm{deg}$ for $\omega_{1}=200 \cdot 2 \pi \mathrm{rad} / \mathrm{s}$, while $\phi_{2}=-\phi_{p}$ for $\omega_{2}=\omega_{r}$.

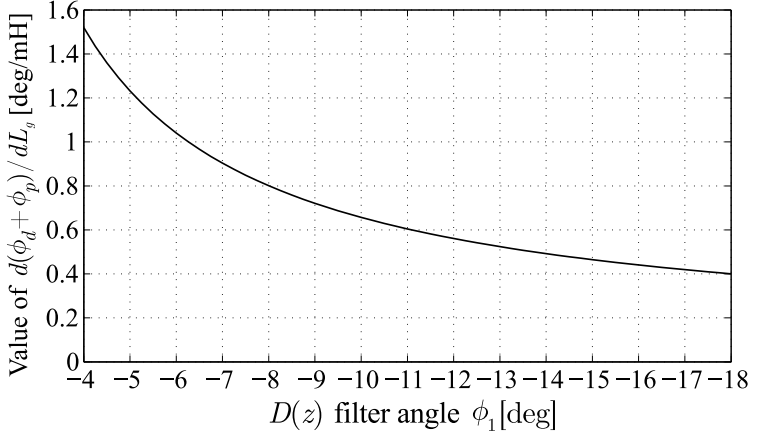

Fig. 15. Value of $d\left(\phi_{d}+\phi_{p}\right) / d L_{g}$ when $\phi_{1}$ changes. The lower the value, the more robust the closed-loop system against changes in $L_{g}$.
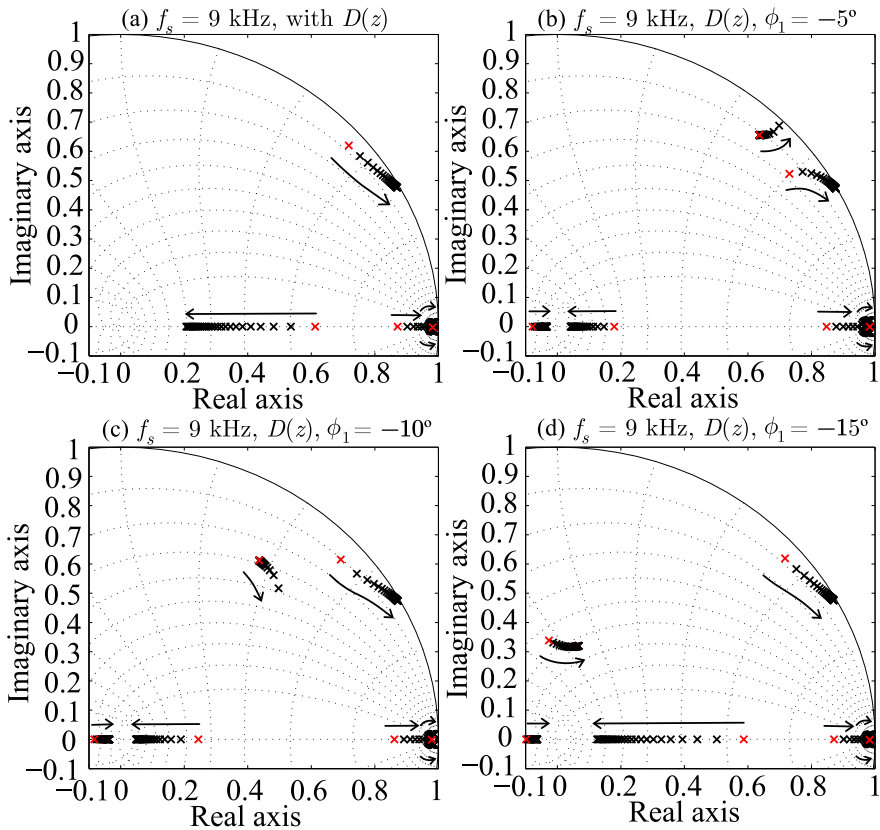

Fig. 16. Closed-loop poles with (a) $D(z)$ based on a first-order all-pass filter, and $D(z)$ based on a second-order all-pass filter with (b) $\phi_{1}=-5$, (c) $\phi=-10$, and (d) $\phi_{1}=-15 \mathrm{deg}$, at $\omega_{1}=200 \cdot 2 \pi \mathrm{rad} / \mathrm{s}$. $L_{g}$ varies from 0 to $0.4 \mathrm{pu}(0$ to $13.5 \mathrm{mH})$. Arrows point to the maximum value of $L_{g}$.

filter coefficients are obtained by solving (23). For example, for $\phi_{1}=-10 \mathrm{deg}: a_{0}=1, a_{1}=-0.8732$, and $a_{2}=0.5707$.

Fig. 14 shows the open-loop frequency response of $G_{2}(z)$ with a second-order filter, for $\phi_{1}=-5,-10$, and $-15 \mathrm{deg}$. The controller $C_{2}(z)$ is designed with $\phi_{m}=45 \mathrm{deg}$. The lower the value of $\phi_{1}$ is, the higher $\omega_{u}$.

\section{Weak Grid Conditions}

Fig. 15 shows the value of $d\left(\phi_{p}+\phi_{d}\right) / d L_{g}$ when $\phi_{1}$ changes: the lower the value of $\phi_{1}$, the less robust the closedloop system. Additionally, Fig. 16 shows the closed-loop poles when $L_{g}$ varies from 0 to 0.4 pu $(0$ to $13.5 \mathrm{mH})$ for a firstorder all-pass filter, and for a second-order filter designed with $\phi_{1}=-5,-10$, and $-15 \mathrm{deg}$. The closed-loop systems are stable regardless the filter used. However, the results with a first-order $D(z)$ and with a second-order $D(z)$ designed with $\phi_{1}=-15 \mathrm{deg}$ are the most robust solutions. 

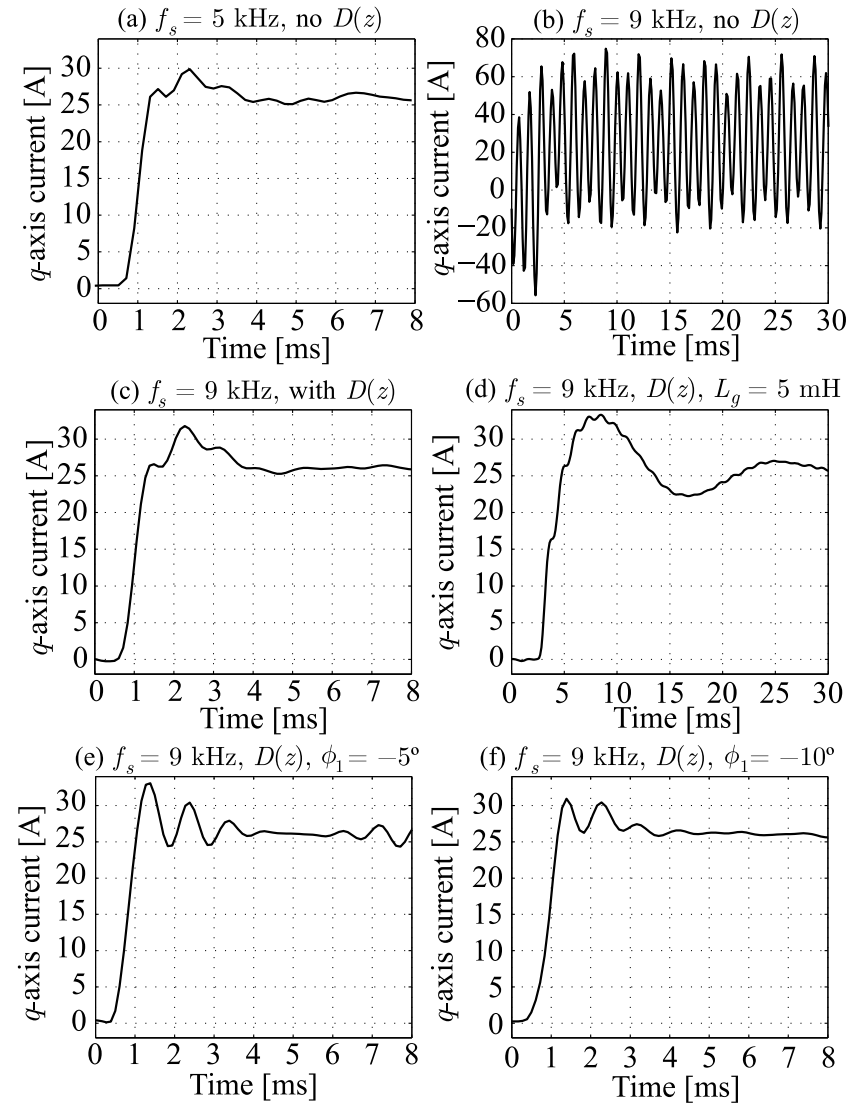

Fig. 17. Simulation results of the closed-loop system for (a) $f_{s}=5 \mathrm{kHz}$ and $f_{s}=9 \mathrm{kHz}(\mathrm{b})$ without and (c) with $D(z)$ based on a first-order allpass filter. (d) $f_{s}=9 \mathrm{kHz}$ with $D(z)$ and $L_{g}=5 \mathrm{mH}$. $f_{s}=9 \mathrm{kHz}$ with $D(z)$ based on a second-order all-pass filter and (e) $\phi_{1}=-5$ deg and (f) $\phi_{1}=-10 \mathrm{deg}$ at $\omega_{1}=200 \cdot 2 \pi \mathrm{rad} / \mathrm{s}$.

\section{Simulation Results}

Fig. 17 shows the simulation results for step changes in $i_{2-q}^{*}$. Fig. 17 (a) shows the results when $f_{s}=5 \mathrm{kHz}$. The transient is fast and oscillations are well damped. Fig. 17 (b) shows the same experiment, but with $f_{s}=9 \mathrm{kHz}$. There are large oscillations in the grid current and the system is close to instability. Fig. 17 (c) shows the results when $f_{s}=9 \mathrm{kHz}$, but in this case $D(z)$ is applied. The transient is well damped and the oscillation in Fig. 17 (b) has disappeared. The transient response is very similar to that in Fig. 17 (a). Fig. 17 (d) shows the transient response when $f_{s}=9 \mathrm{kHz}$ with $D(z)$ and $L_{g}=5 \mathrm{mH}\left(R_{g}=0 \Omega\right)$. The transient response is slow, but the closed-loop system is stable and the resonance is still damped. Fig. 17 (e-f) show the step response when $D(z)$ is a second-order all-pass filter designed with (e) $\phi_{1}=-5$ and (f) $\phi_{1}=-10 \mathrm{deg}$. The closer is $\phi_{1}$ to zero, the faster the transient response. However, for $\phi_{1}=-5 \mathrm{deg}$ the oscillation in the output current is not very well damped.

\section{Experimental Results: Proposed Method}

1) Active Damping Provided at the Design Stage: The sampling frequency is $f_{s}=5 \mathrm{kHz}$, so active damping is provided at the design stage, as shown in Fig. $12(D(z)$ is not necessary). Fig. 18 (top) shows the transient performance

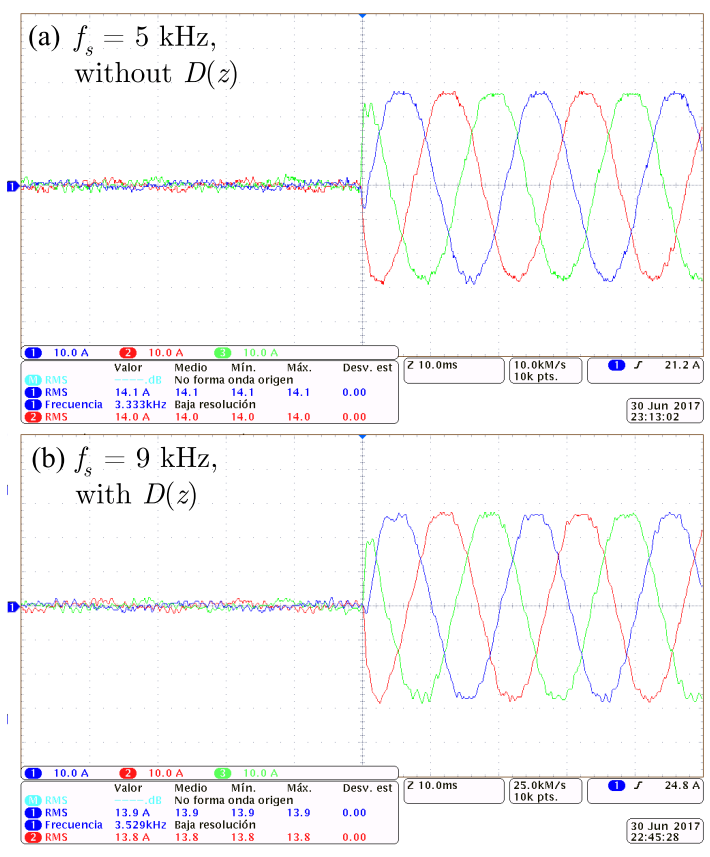

Fig. 18. Output current $\left(i_{2}(t)\right)$ for a step-change in $i_{2-q}^{*}[k]$ when (a) $f_{s}=5 \mathrm{kHz}$ and (b) $f_{s}=9 \mathrm{kHz}$ with $D(z)$ (first order).

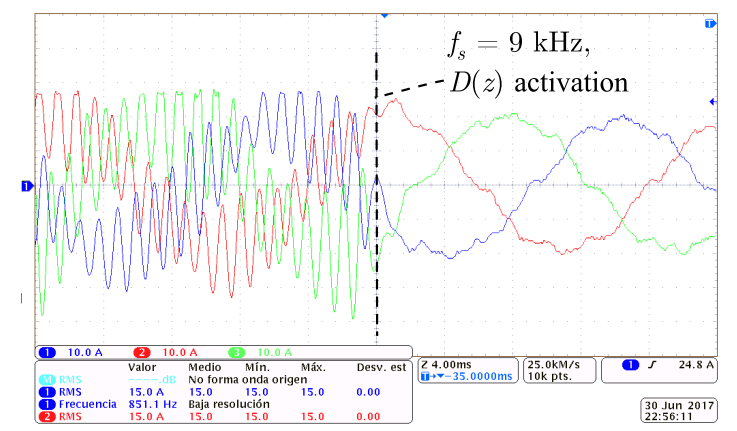

Fig. 19. Converter output current for $f_{s}=9 \mathrm{kHz}$ when $D(z)$ (first order) is connected in series with the current controller.

of the VSC when the $i_{2-q}^{*}$ is changed from 0 to 15 A (RMS). It is worth pointing out that the current has harmonic distortion because the grid is distorted. It can be seen that the transient response of the closed-loop system is perfectly damped and that there are no oscillations in the output current. The current THD is $3.6 \%$, and the VSC efficiency $95.9 \%$ (measured at nominal current).

2) Active Damping with First-Order All-Pass Filters:

Fig. 19 shows the VSC output current when $D(z)$ is connected in series with the current controller. The sampling frequency is $f_{s}=9 \mathrm{kHz}$ (see Fig. 13). The high-frequency oscillation disappears when $D(z)$ is connected. Fig. 18 (bottom) shows the transient performance of the VSC when the $q$-axis setpoint is modified from 0 to $15 \mathrm{~A}$ (RMS). It can be seen that the transient response is slightly slower compared to the one in Fig. 18 (top), but sill fast. The current THD is $3.0 \%$, and the efficiency of the VSC is $95.6 \%$. Compared to the previous case (damping provided at the design stage), the THD is slightly better. This is because the switching frequency is $9 \mathrm{kHz}$, while for the other case it was $5 \mathrm{kHz}$. Conversely, the 


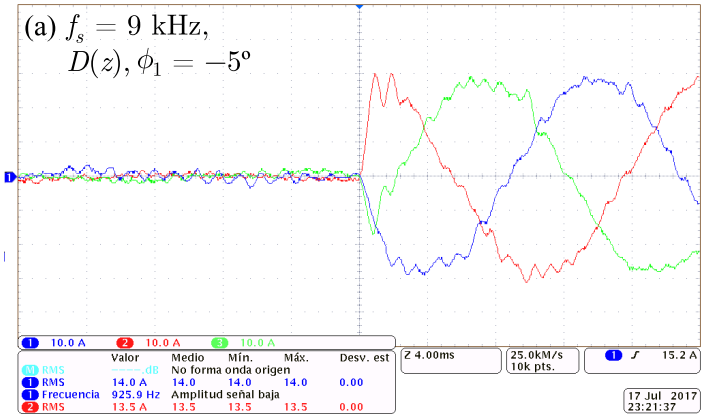

(b) $f_{s}=9 \mathrm{kHz}$, $D(z), \phi_{1}=-10^{\circ}$

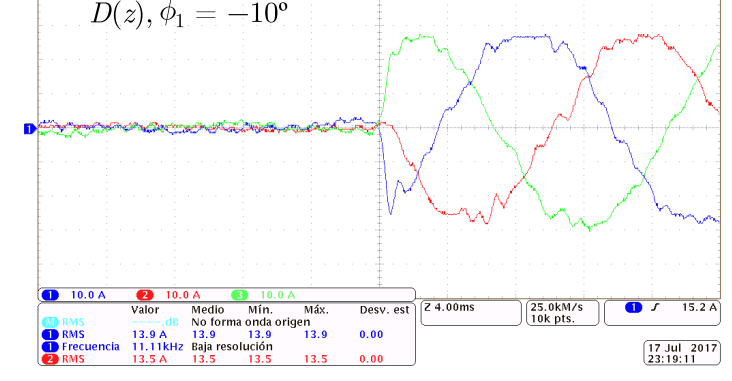

Fig. 20. Converter output current for $f_{s}=9 \mathrm{kHz}$ when $D(z)$ is a secondorder all-pass filter with (top) $\phi_{1}=-5$ and (bottom) $\phi_{1}=-10 \mathrm{deg}$.

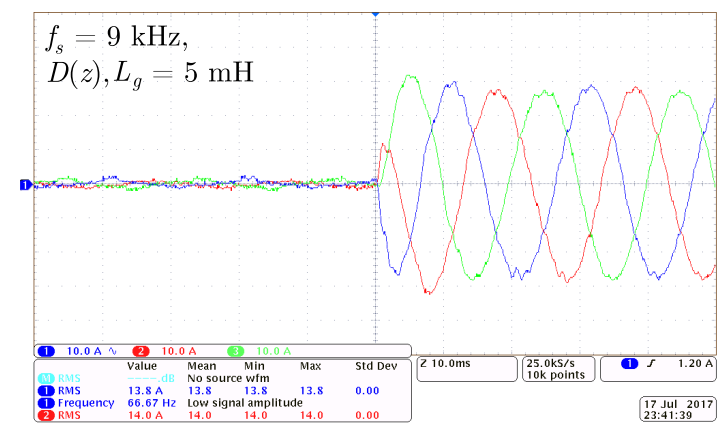

Fig. 21. Converter output current for $f_{s}=9 \mathrm{kHz}$ when $D(z)$ is a first-order all-pass filter and $L_{g}=5 \mathrm{mH}$.

efficiency slightly decreases due to the additional switching losses.

3) Active Damping with Second-Order All-Pass Filters: Fig. 21 shows the transient response when a second order allpass filter is used ( $\phi_{1}=-5 \mathrm{deg}$ and $\left.\phi_{1}=-10 \mathrm{deg}\right)$. It can be seen that the transient is slightly faster when $\phi_{1}$ approaches zero. However, the THD is $3.7 \%$ and the efficiency is $95.2 \%$ for $\phi_{1}=-5 \mathrm{deg}$, while the THD is $3.4 \%$ and the efficiency is $95.4 \%$ for $\phi_{1}=-10 \mathrm{deg}$. This reveals that the resonance is less damped compared to the first-order all filter case.

4) Active Damping with Weak Grid Conditions: Fig. 21 shows the transient response when $L_{g}=5 \mathrm{mH}$ and a firstorder all-pass filter is used $\left(f_{s}=9 \mathrm{kHz}\right)$. It is worth pointing out that the current has harmonic distortion because the grid is distorted. The transient is slow, mainly due to the PI controller detune. However, the high-frequency oscillation is still damped.
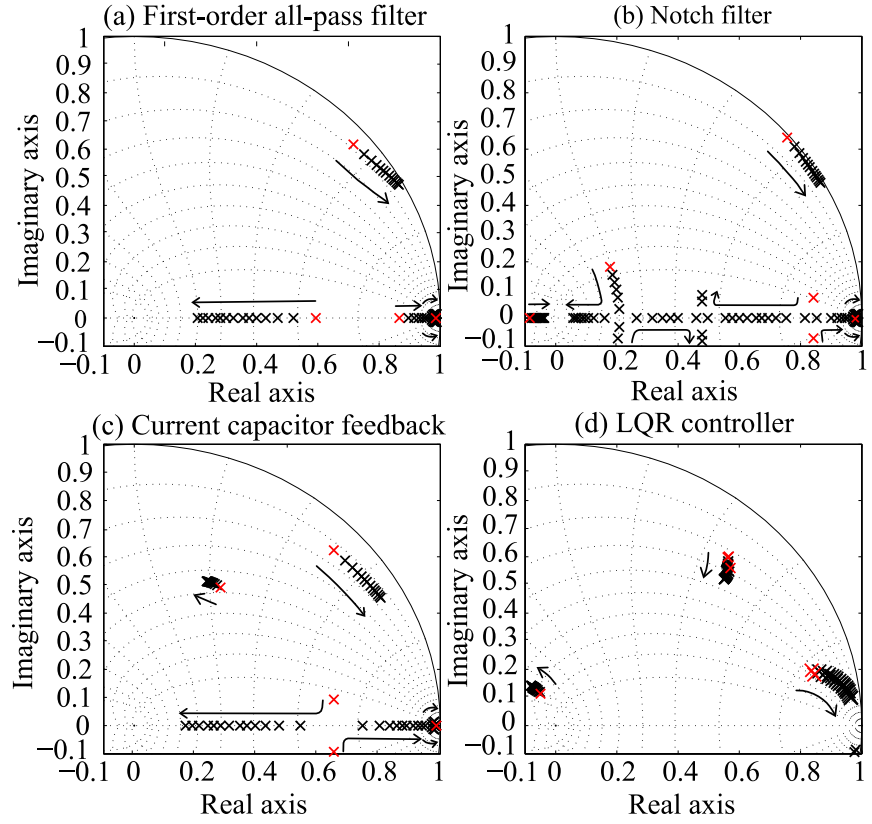

Fig. 22. Closed-loop poles with (a) a first-order all-pass filter, (b) a notch filter, (c) a current capacitor feedback, and (d) a LQR controller. $L_{g}$ varies from 0 to $0.4 \mathrm{pu}$ ( 0 to $13.5 \mathrm{mH}$ ). Arrows point to the maximum value of $L_{g}$.

\section{Comparative Analysis}

\section{A. Robustness Against Grid Inductance Variations}

Fig. 22 shows the closed-loop poles for the alternative active damping solutions when $L_{g}$ is modified. First of all, with the notch filter the damping factor of the resonant poles is small, even for $L_{g}=0 \mathrm{mH}$. When the grid inductance increases the resonant poles are always stable, but they remain very close to the unstable region. For the current-capacitor feedback controller, the resonant poles are well damped and the damping factor remains almost constant when the grid inductance increases. It can be seen that the low-frequency dynamics of alternatives (a), (b), and (c) are very similar. Finally, the LQR controller gives an outstanding damping of the resonant poles. Meanwhile, the low-frequency poles approach zero when $L_{g}$ increases. The results obtained with the LQR controller are clearly more robust compared to those obtained with the other control alternatives. For the single loop control strategies (all-pass filter and notch), the all-pass filter gives a better attenuation of the resonance.

\section{B. Experimental Results}

Fig. 23 shows the transient responses obtained with the alternative controllers when the grid is weak $\left(L_{g}=5 \mathrm{mH}\right)$ and a step-change is applied to $i_{2-q}^{*}$. The transient response obtained with the notch filter is the slowest one, and it has a large overshoot. The THD is $2.4 \%$. With the capacitor current feedback, the transient is smooth and it does not have overshoot. The THD is $2.2 \%$. Finally, the LQR provides the fastest transient, but the THD slightly increases up to $2.7 \%$.

\section{CONCLUSiON}

This paper has shown a method to damp the resonance of $L C L$ filters with a single control loop that is based on 


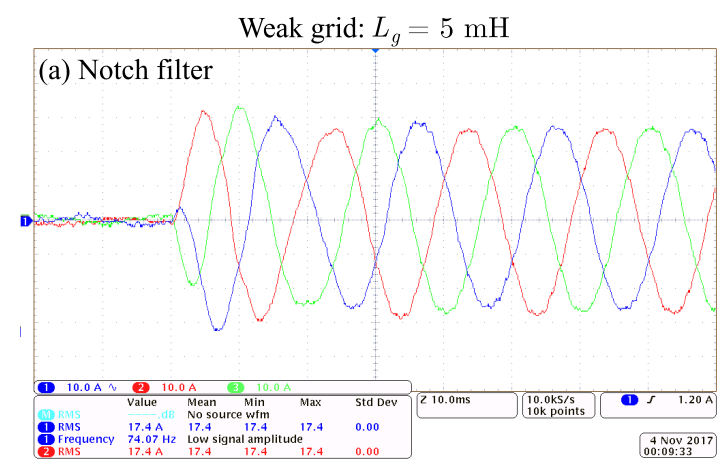

(b) Capacitor current feedback

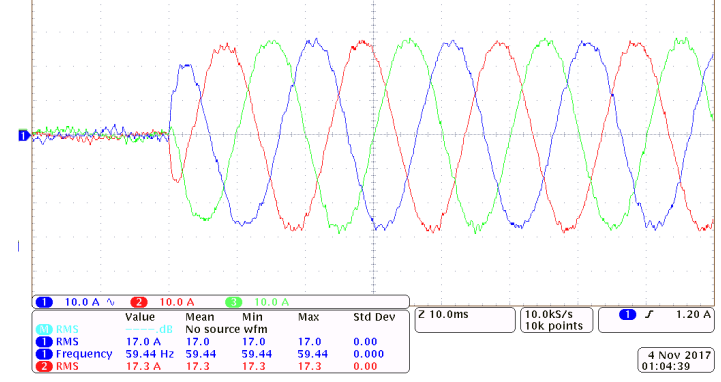

(c) LQR controller

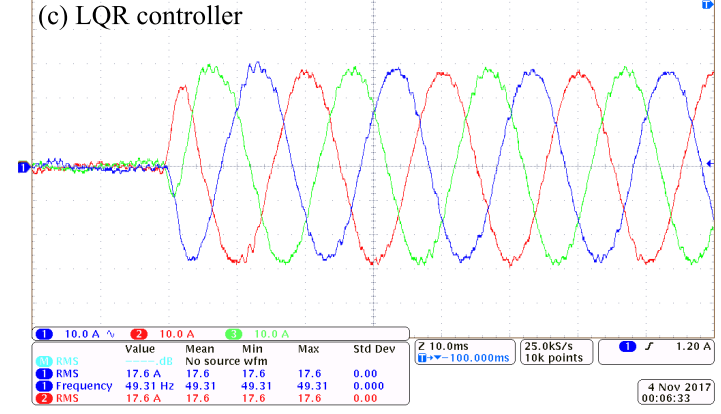

Fig. 23. Transient performance of the alternatives under weak grid conditions. (a) Notch filter, (b) capacitor current feedback, and (c) LQR controller.

making zero the open-loop phase at the resonance frequency. It has been shown that this goal can be achieved at the design stage by changing a) the sampling period or b) the resonance frequency. However, when this is not possible, a solution based on all-pass filters has been proposed. All the proposed control improvements have been verified theoretically, by simulation, and in a $15 \mathrm{~kW}$ prototype of a VSC connected to a configurable weak grid.

It has been shown that the simplest solution is to guarantee stability at the design stage: this simplifies the PI controller design and makes it possible to achieve fast transient responses because no additional additional delays are added to the control loop. However, when this alternative cannot be applied due to design constraints, a first-order all-pass filter is a simple solution. This alternative is robust, but it slightly slows down the transient response. If faster transient responses are required, a second-order all-pass filter can be applied. However, with the second-order all-pass filter the closed-loop system is less robust when the VSC is connected to a weak grid and the current THD worsens.

The proposed active damping method has been compared with three popular alternatives: a notch filter, a capacitor- current feedback, and a LQR controller. The notch filter makes the closed-loop system stable, but the closed-loop poles are not very well damped. However, the THD is low. With the capacitor current feedback the closed-loop poles are well damped regardless the grid inductance value. However, an additional measurement is required. Finally, the LQR controller provides the best transient performance and robustness against grid inductance variations. However, all the system state variables must be measured unless a state observer is used.

\section{ACKNOWLEDGEMENTS}

This work presented has received financial support by the Community of Madrid Government, Spain, through the research project PRICAM (S2013/ICE-2933). Thanks are due to Milan Prodanovic for his comments on this paper and to Norvento Energía Distribuida.

\section{REFERENCES}

[1] A. Yazdani and R. Iravani, Voltage-Sourced Converters in Power Systems. Wiley, 2010.

[2] "Electromagnetic Compatibility (EMC) - Part 3-4: Limits - limitation of emission of harmonic currents in low-voltage power supply systems for equipment with rated current greater than 16 A." IEC-61000-3-4, 1998.

[3] "IEEE recommended practice and requirements for harmonic control in electric power systems," IEEE Std 519-2014, pp. 1-29, June 2014.

[4] M. T. Bina and E. Pashajavid, "An efficient procedure to design passive LCL-filters for active power filters," Electric Power Systems Research, vol. 79, no. 4, pp. 606-614, 2009.

[5] R. Peña-Alzola, M. Liserre, F. Blaabjerg, R. Sebastián, J. Dannehl, and F. W. Fuchs, "Analysis of the passive damping losses in LCL-filter-based grid converters," IEEE Transactions on Power Electronics, vol. 28, no. 6, pp. 2642-2646, June 2013.

[6] R. N. Beres, X. Wang, F. Blaabjerg, M. Liserre, and C. L. Bak, "Optimal design of high-order passive-damped filters for grid-connected applications," IEEE Transactions on Power Electronics, vol. 31, no. 3, pp. 2083-2098, March 2016.

[7] R. Peña-Alzola, M. Liserre, F. Blaabjerg, R. Sebastián, J. Dannehl, and F. W. Fuchs, "Systematic design of the lead-lag network method for active damping in LCL-filter based three phase converters," IEEE Transactions on Industrial Informatics, vol. 10, no. 1, pp. 43-52, Feb 2014.

[8] Y. A. R. I. Mohamed, M. A. Rahman, and R. Seethapathy, "Robust line-voltage sensorless control and synchronization of LCL-filtered distributed generation inverters for high power quality grid connection," IEEE Transactions on Power Electronics, vol. 27, no. 1, pp. 87-98, Jan 2012.

[9] T. N. Nguyen, A. Luo, and M. Li, "A simple and robust method for designing a multi-loop controller for three-phase VSI with an LCL-filter under uncertain system parameters," Electric Power Systems Research, vol. 117, pp. 94-103, 2014.

[10] X. Bao, F. Zhuo, Y. Tian, and P. Tan, "Simplified feedback linearization control of three-phase photovoltaic inverter with an LCL filter," IEEE Transactions on Power Electronics, vol. 28, no. 6, pp. 2739-2752, June 2013.

[11] M. Ochoa-Giménez, A. García-Cerrada, and J. L. Zamora-Macho, "Comprehensive control for unified power quality conditioners," Journal of Modern Power Systems and Clean Energy, vol. 5, no. 4, pp. 609-619, Jul 2017.

[12] X. Wang, F. Blaabjerg, and P. C. Loh, "Virtual RC damping of LCLfiltered voltage source converters with extended selective harmonic compensation," IEEE Trans. on Power Electronics, vol. 30, no. 9, pp. 4726-4737, Sept 2015.

[13] X. Wang, C. Bao, X. Ruan, W. Li, and D. Pan, "Design considerations of digitally controlled LCL-filtered inverter with capacitor-current-feedback active damping," IEEE Journal of Emerging and Selected Topics in Power Electronics, vol. 2, no. 4, pp. 972-984, Dec 2014.

[14] J. Roldán-Pérez, A. García-Cerrada, J. L. Zamora-Macho, and M. Ochoa-Giménez, "Helping all generations of photo-voltaic inverters ride-through voltage sags," IET Power Electronics, vol. 7, no. 10, pp. 2555-2563, 2014. 
[15] B. C. Kuo and F. Golnaraghi, Automatic Control Systems, 8th ed. New York, NY, USA: John Wiley \& Sons, Inc., 2002.

[16] F. Huerta, D. Pizarro, S. Cobreces, F. J. Rodriguez, C. Giron, and A. Rodriguez, "LQG servo controller for the current control of LCL gridconnected voltage-source converters," IEEE Transactions on Industrial Electronics, vol. 59, no. 11, pp. 4272-4284, Nov 2012.

[17] C. A. Busada, S. G. Jorge, and J. A. Solsona, "Full-state feedback equivalent controller for active damping in LCL-filtered grid-connected inverters using a reduced number of sensors," IEEE Transactions on Industrial Electronics, vol. 62, no. 10, pp. 5993-6002, Oct 2015.

[18] Y. W. Li, B. Wu, N. R. Zargari, J. C. Wiseman, and D. Xu, "Damping of pwm current-source rectifier using a hybrid combination approach," IEEE Transactions on Power Electronics, vol. 22, no. 4, pp. 1383-1393, July 2007.

[19] W. Yao, Y. Yang, X. Zhang, F. Blaabjerg, and P. C. Loh, "Design and analysis of robust active damping for LCL filters using digital notch filters," IEEE Transactions on Power Electronics, vol. 32, no. 3, pp. 2360-2375, March 2017.

[20] X. Wang, F. Blaabjerg, and P. C. Loh, "Grid-current-feedback active damping for LCL resonance in grid-connected voltage-source converters," IEEE Trans. on Power Electronics, vol. 31, no. 1, pp. 213-223, Jan 2016.

[21] X. Fu and S. Li, "Control of single-phase grid-connected converters with LCL filters using recurrent neural network and conventional control methods," IEEE Transactions on Power Electronics, vol. 31, no. 7, pp. 5354-5364, July 2016.

[22] H. Komurcugil, S. Ozdemir, I. Sefa, N. Altin, and O. Kukrer, "Slidingmode control for single-phase grid-connected LCL-filtered VSI with double-band hysteresis scheme," IEEE Transactions on Industrial Electronics, vol. 63, no. 2, pp. 864-873, Feb 2016

[23] Y. Lyu, H. Lin, and Y. Cui, "Stability analysis of digitally controlled LCL-type grid-connected inverter considering the delay effect," IET Power Electronics, vol. 8, no. 9, pp. 1651-1660, 2015.

[24] J. Wang, J. D. Yan, L. Jiang, and J. Zou, "Delay-dependent stability of single-loop controlled grid-connected inverters with LCL filters," IEEE Trans. on Power Electronics, vol. 31, no. 1, pp. 743-757, Jan 2016

[25] C. Chen, J. Xiong, Z. Wan, J. Lei, and K. Zhang, "A time delay compensation method based on area equivalence for active damping of an LCL-type converter," IEEE Transactions on Power Electronics, vol. 32, no. 1, pp. 762-772, Jan 2017.

[26] J. Roldán-Pérez, E. Bueno, R. Peña-Alzola, and A. Rodríguez-Cabero, "Single-loop all-pass-filter-based active damping for VSCs with LCL filters connected to the grid," in IEEE Energy Conversion Congress \& Exposition (ECCE) 2017, October 2017.

[27] B. Kuo, Digital Control Systems. Oxford University Press, 1992.

[28] J. Roldán-Pérez, A. García-Cerrada, J. L. Zamora-Macho, P. RonceroSánchez, and E. Acha, "Troubleshooting a digital repetitive controller for a versatile dynamic voltage restorer," International Journal of Electrical Power \& Energy Systems, vol. 57, no. 0, pp. 105-115, 2014.

[29] T. Laakso, V. Valimaki, M. Karjalainen, and U. Laine, "Splitting the unit delay [FIR/all pass filters design]," IEEE Signal Processing Magazine, vol. 13 , no. 1, pp. 30-60, 1996.

[30] R. Peña-Alzola, M. Liserre, F. Blaabjerg, M. Ordonez, and T. Kerekes, "A self-commissioning notch filter for active damping in a threephase LCL-filter-based grid-tie converter," IEEE Transactions on Power Electronics, vol. 29, no. 12, pp. 6754-6761, Dec 2014.

[31] Y. W. Li, "Control and resonance damping of voltage-source and current-source converters with filters," IEEE Transactions on Industrial Electronics, vol. 56, no. 5, pp. 1511-1521, 2009.

[32] S. Skogestad and I. Postlethwaite, Multivariable Feedback Control: Analysis and Design. John Wiley \& Sons, 2005.

[33] A. Rodríguez-Cabero, F. H. Sánchez, and M. Prodanovic, "A unified control of back-to-back converter," in 2016 IEEE Energy Conversion Congress and Exposition (ECCE), Sept 2016, pp. 1-8.

[34] F. Huerta, J. K. Gruber, M. Prodanovic, and P. Matatagui, "Powerhardware-in-the-loop test beds: evaluation tools for grid integration of distributed energy resources," IEEE Industry Applications Magazine, vol. 22, no. 2, pp. 18-26, March 2016.

[35] M. Prodanovic, A. Rodríguez-Cabero, M. Jiménez-Carrizosa, and J. Roldán-Pérez, "A rapid prototyping environment for DC and AC microgrids: Smart Energy Integration Lab (SEIL)," in 2017 IEEE Second International Conference on DC Microgrids (ICDCM), June 2017, pp. $421-427$.

[36] M. Alakula and A. Carlsson, "An induction machine servo with one current controller and an improved flux observer," in Industrial Electronics, Control, and Instrumentation, 1993. Proceedings of the IECON '93., International Conference on, Nov 1993, pp. 1991-1996 vol.3.

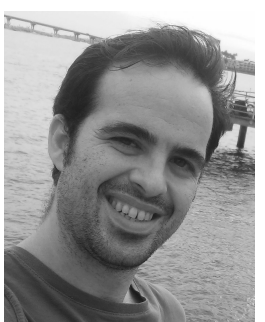

Javier Roldán-Pérez received a B.S. degree in industrial engineering, a M.S. degree in electronics and control systems, a M.S. degree in system modeling, and a Ph.D. degree in power electronics, all from Comillas Pontifical University, Madrid, in $2009,2010,2011$, and 2015, respectively. From 2010 to 2015 , he was with the Institute for Research in Technology (IIT), Comillas University. In 2014, he was a visiting Ph.D. student at the Department of Energy Technology, Aalborg University, Denmark. From 2015 to 2016 he was with the Electric and Control Systems Department at Norvento Energa Distribuida. In September 2016 he joined the Electrical Systems Unit at IMDEA Energy Institute, where his research topics are the integration of renewable energies, microgrids, and power electronics applications.

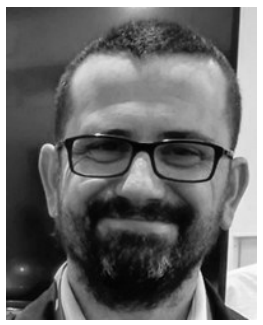

Emilio J. Bueno (S05M06) was born in Madrid, Spain, in 1972. He received the M.S. and Ph.D. degrees in electronics engineering from the University of Alcalá, Alcalá de Henares, Spain, in 1999 and 2005, respectively. Since 2009, he has been an Associate Professor with the Department of Electronics, University of Alcalá, and a member of the Electronics Engineering Applied to Renewable Energies Research Group. From 2010 to 2013, he was a Vice-Dean of the Polytechnic School, University of Alcalá, in charge of electrical engineering studies. His research interests include linear control of grid converters and drives, power quality, distributed generation systems, and medium-voltage converter topologies.

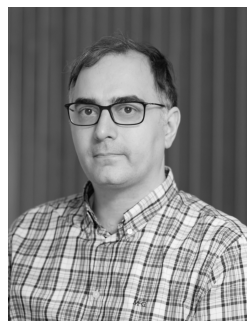

Rafael Peña-Alzola received the combined licentiate and M.Sc. degree in industrial engineering from the University of the Basque Country, Bilbao, Spain, in 2001, and the Ph.D. degree from the National University for Distance Learning (UNED), Madrid, Spain, in 2011. He has worked as an electrical engineer for several companies in Spain. From September 2012 to July 2013, he was Guest Postdoc at the Department of Energy Technology at Aalborg University in Aalborg, Denmark. From August 2014 to December 2016, he was Postdoc Research Fellow at the Department of Electrical and Computer Engineering at The University of British Columbia in Vancouver, Canada. From January 2017 to May 2017, he was with the University of Alcala in Madrid, Spain for a short-term industrial collaboration.

Since June 2017, he is Research Fellow at the Rolls Royce University Technology Centre at the University of Strathclyde in Glasgow, UK. His research interests are energy storage, LCL-filters, solid-state transformers, power electronics for hybrid electric aircraft and innovative control techniques for power converters.

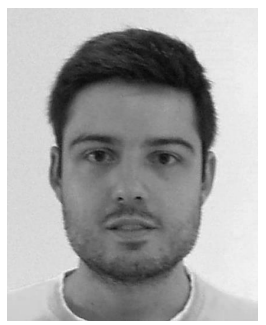

Alberto Rodríguez-Cabero obtained his degrees in Industrial Technical Engineering and Industrial Engineering specialized in Electronics in 2011 and 2013, respectively, both from Comillas Pontifical University. In 2016, he obtained the Master in Research in Engineering Systems Modelling in the same University. From 2014 to 2015 , he worked as control engineer at Institute for Research in Technology (IIT), Comillas Pontifical University, Madrid. Since September 2015 he is working in the Electrical Systems Unit, Institute IMDEA Energy, Madrid. His areas of interest include the design and control of power electronics converters, power quality and micro-grids. 